\title{
Wasp sting of the cornea
}

This article was published in the following Dove Press journal: International Medical Case Reports Journal

\section{Tetsuya Muto Shigeki Machida}

Department of Ophthalmology, Dokkyo Medical University Saitama Medical Center, Koshigaya, Japan
Correspondence: Tetsuya Muto Department of Ophthalmology, Dokkyo Medical University Saitama Medical Center, 2-I-50, Minami-Koshigaya, Koshigaya, Saitama 343-8555, Japan Tel +8I 48965 IIII

Fax $+8 \mid 48965$ । I 27

Email mutotetsuya@gmail.com
Purpose: Many treatments, such as conservative management or penetrating keratoplasty, exist for corneal wasp sting. Here, we report a case of paper wasp sting of the cornea treated by anterior chamber wash immediately following admission, which soon resolved the inflammation. Case: A healthy 9-year-old boy who had been stung by a paper wasp on his left eye 2 days prior to presentation at Dokkyo Medical University Saitama Medical Center was found to have corneal opacity accompanied by ciliary injection. The boy had difficulty opening his left eye due to pain. His left corneal endothelial cell density was 2,789 cells $/ \mathrm{mm}^{2}$, which was relatively lesser than that in the right eye. We diagnosed a paper wasp sting of the cornea based on both the patient's clinical findings and sting history. The anterior chamber was promptly irrigated using a balanced salt solution; the inflammation resolved in a few hours, and the patient could open his left eye easily the following day. One day after the operation, the visual acuity improved to 1.2 , and only slight corneal opacity remained at the original wasp sting site.

Conclusion: The positive outcome of the current case suggested that anterior chamber irrigation leads to rapid resolution of the inflammation.

Keywords: anterior chamber, endothelial cell density, paper wasp

\section{Introduction}

Wasps belong to the order Hymenoptera. ${ }^{1}$ They tend to target black-colored subjects in general, and therefore black hair and eyes of human beings are their easy targets. Corneal wasp stings occasionally cause corneal erosion, endothelium damage, cataract, and glaucoma. At such instances, surgery may be indicated. ${ }^{2}$

Although the visual prognosis after paper wasp sting of the cornea is generally good, hornet sting of the cornea has a poor prognosis in Japan. ${ }^{3,4}$ For example, five eyes out of eleven in a series lost light perception due to hornet sting of the cornea. ${ }^{5}$ On the other hand, Nakashima et $\mathrm{al}^{6}$ reported that 18 eyes out of 19 had a final visual acuity of $\geq 0.8$ after paper wasp sting of the cornea. Iwami et $\mathrm{al}^{7}$ reported that anterior chamber irrigation is an effective treatment for paper wasp or bee stings of the cornea. However, Nakashima et $\mathrm{al}^{6}$ argued that anterior chamber irrigation was not required to treat paper wasp stings of the cornea because their toxicity was not as severe as that of hornet stings. Ono et $\mathrm{al}^{4}$ reported that the anterior chamber was irrigated in two out of three eyes after hornet sting; however, conservative treatment was performed in two out of two eyes after a paper wasp sting.

We report a case of paper wasp sting of the left cornea treated with anterior chamber irrigation, which soon resolved the inflammation. 


\section{Case report}

A 9-year-old boy presented with a 4-day history of left eye pain and decreased vision due to a paper wasp sting to his left eye. The patient was attacked by a paper wasp while outside on an elementary school playground, because he went near the nest. The patient was prescribed topical levofloxacin $1.5 \%$, fluorometholone $0.1 \%$, and sodium hyaluronate $0.1 \%$ at a previous eye clinic. This treatment provided little relief, and the boy developed a corneal infiltrate with surrounding edema. Corneal edema occurred only in the area of the sting. A bee sting could not be found on the cornea. The anterior chamber showed mild flares and cells.

On clinical examination, his best-corrected visual acuity (BCVA) was 1.2 in the right eye, which was within normal limits, and 0.8 in the left eye. The left eye showed a paracentral corneal infiltrate with surrounding edema (Figure 1). The lens was clear, and posterior segment examination was unremarkable. The intraocular pressure was $12 \mathrm{mmHg}$ in the left eye, and corneal endothelial cell densities (CECDs) were 3,083 cells $/ \mathrm{mm}^{2}$ in the right eye and 2,789 cells $/ \mathrm{mm}^{2}$ in the left eye (Figure 2). It was difficult for the patient to open his left eye.

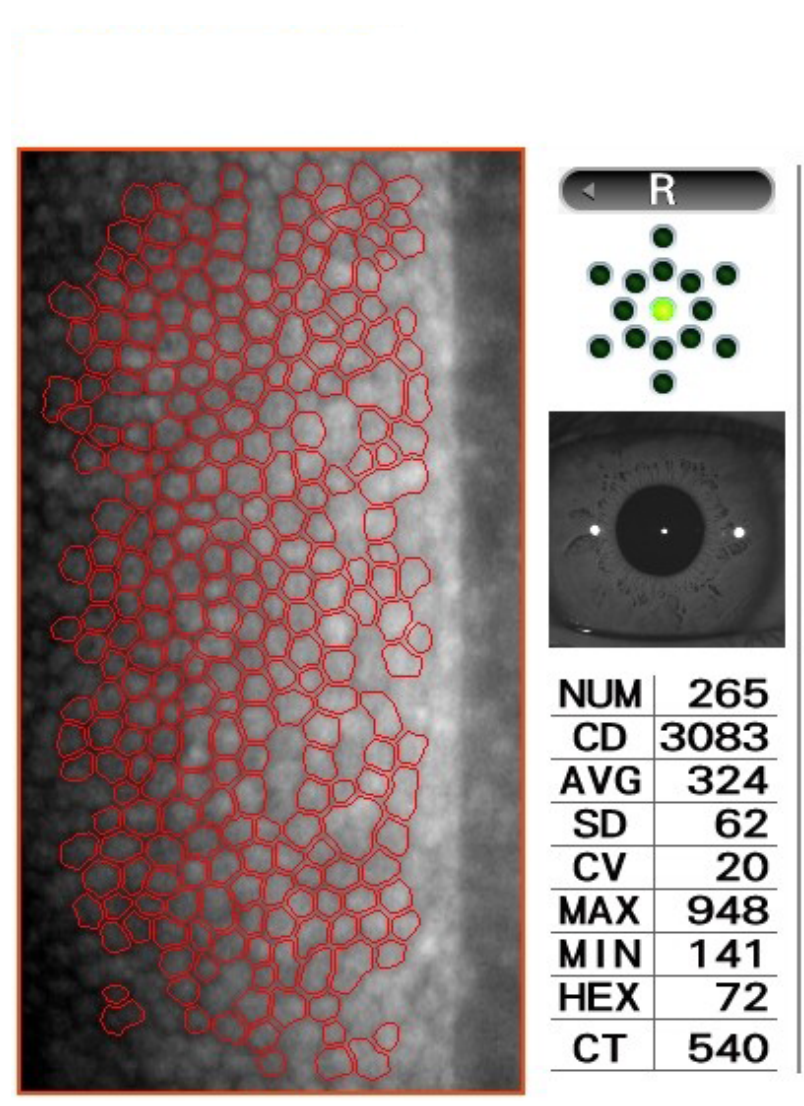

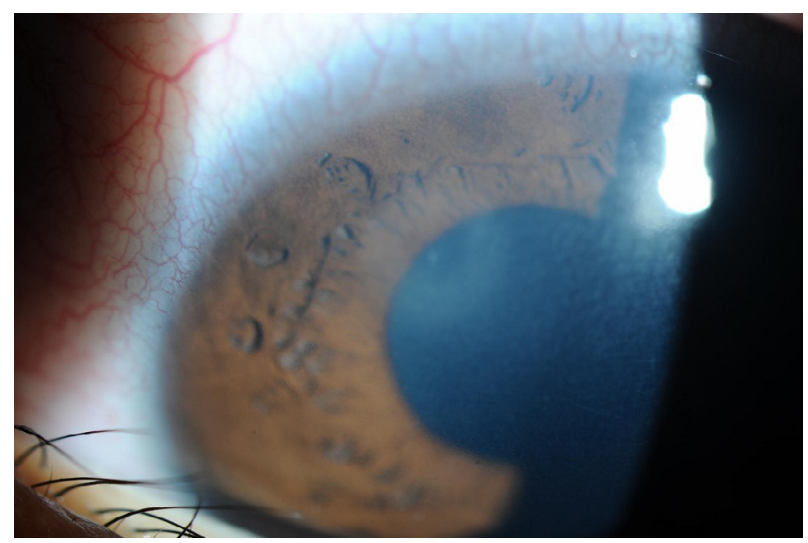

Figure I Photograph of a 9-year-old Japanese boy showing corneal infiltrate with surrounding edema in the right eye.

We promptly washed the anterior chamber under general anesthesia. The inflammation resolved within hours after the procedure, and the patient could easily open his left eye the following day. His BCVA improved to 1.2, 1 day after the surgery. Fluorometholone $0.1 \%$ eye drops were applied 4 times/day for 1 month after the surgery. Thereafter, fluorometholone $0.02 \%$ eye drops were applied 4 times/day for 2 months and were then discontinued.

2017/08/10 10:49:06

No. : 4642
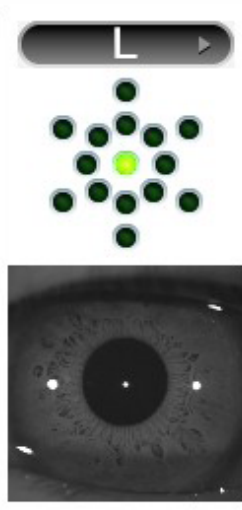

NUM 110

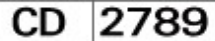

AVG 359

SD 95

CV 28

MAX 1017

MIN 135

HEX 68

CT 602

Figure 2 Specular microscopy showing CECD of both eyes at the initial visit.

Abbreviations: AVG, average area; CECD, corneal endothelial cell density; CD, cell density; CT, corneal thickness; CV, coefficient of variation; HEX, hexagonal; MAX, maximum area; MIN, minimum area; NUM, number of cells. 
Twelve months later, the patient's BCVA was still 1.2, and slight corneal opacity remained at the original paper wasp sting site (Figure 3). CECD in the left eye, at 2,798 cells $/ \mathrm{mm}^{2}$, was also comparatively lesser than in the right (Figure 4).

\section{Discussion}

In Japan, ophthalmologists generally avoid performing anterior chamber irrigation for paper wasp stings ${ }^{5}$ because

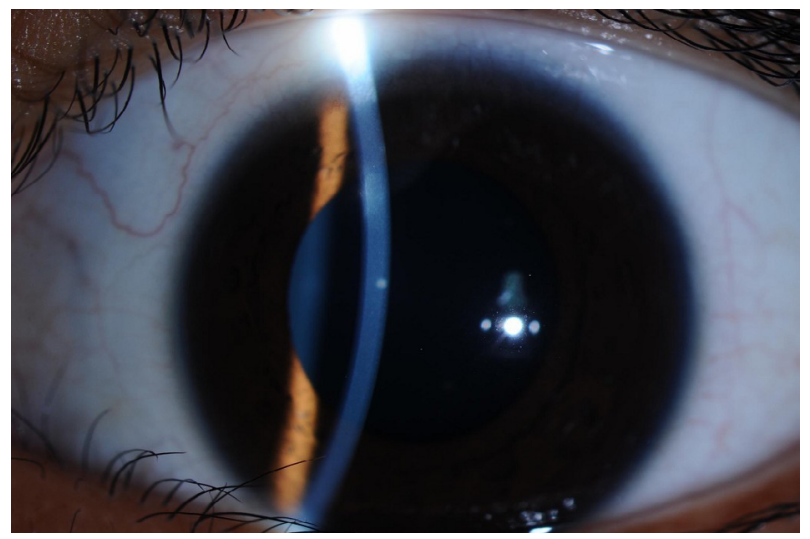

Figure 3 Twelve months after the initial visit, there is slight corneal opacity in the patient's right eye.

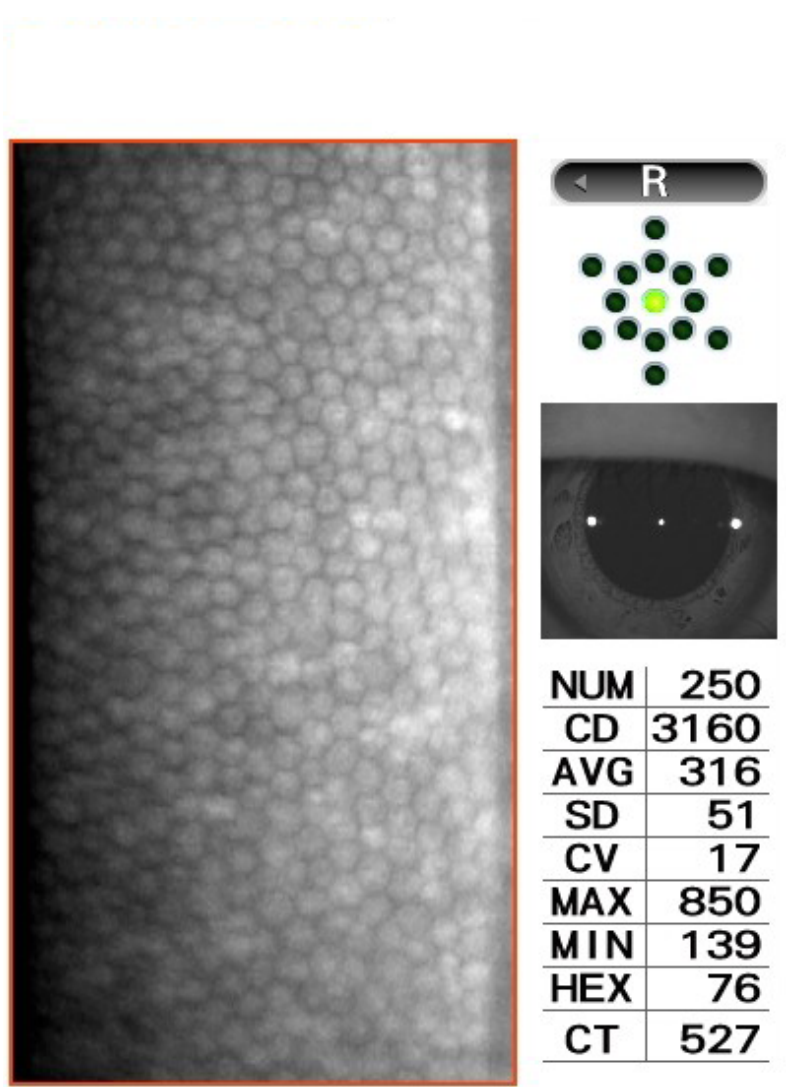

the visual prognosis of paper wasp sting of the cornea is better than that of hornet sting of the cornea. ${ }^{3,4}$ Anterior chamber irrigation is an invasive treatment and occasionally causes severe complications such as infection; therefore, these reservations are warranted. However, we decided to remove the paper wasp venom from the anterior chamber by directly washing, and our experience showed that this method was very effective because it led to the rapid resolution of the inflammation. Thus, anterior chamber irrigation seems to be a treatment option for paper wasp sting of the cornea.

Although CECD before the wasp sting was unknown, the stung eye showed an approximately $10 \%$ lower CECD than that of the unaffected right eye. Irrigation of the anterior chamber may influence this CECD reduction. Furthermore, our patient does not indicate a history of other eye trauma or uveitis; therefore, the wasp venom is the most probable cause of the CECD reduction. Wasp venom is composed of various peptides and proteins such as melittin, phospholipase A2, apamin, and mast cell degranulating peptide., ${ }^{8,9}$ The mechanism of CECD reduction by wasp sting remains

2018/08/04 09:19:48

No. : 9063
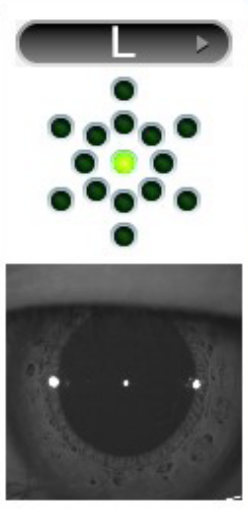

NUM 245

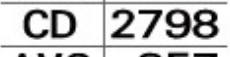

AVG 357

\begin{tabular}{l|r}
\hline SD & 64 \\
\hline
\end{tabular}

\begin{tabular}{l|r}
\hline CV & 19 \\
\hline
\end{tabular}

\begin{tabular}{l|l}
\hline MAX & $\mathbf{8 2 7}$ \\
\hline
\end{tabular}

\begin{tabular}{l|r}
\hline MIN & 151 \\
\hline
\end{tabular}

\begin{tabular}{ll}
\hline HEX & 77 \\
\hline
\end{tabular}

CT 529

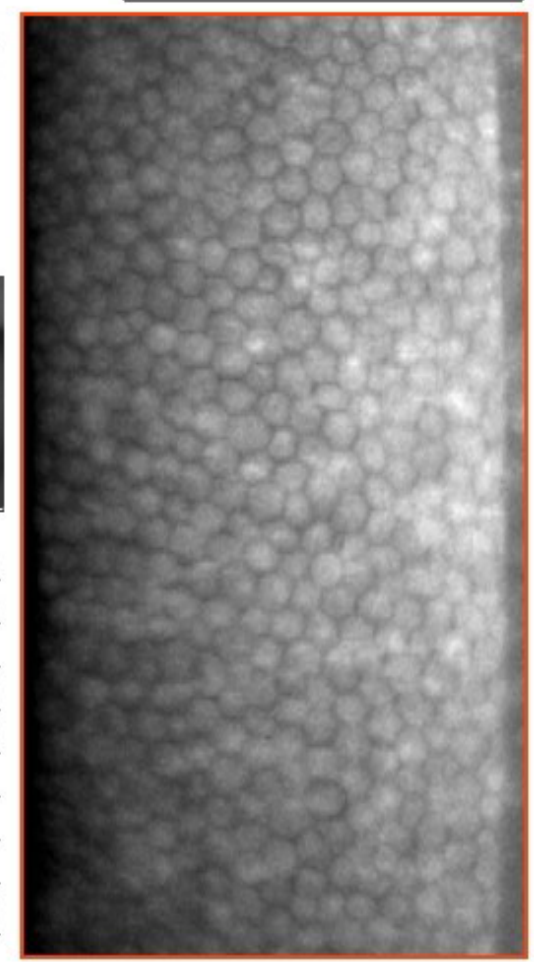

Figure 4 Specular microscopy showing CECDs of both eyes at 12 months after the initial visit.

Note: CECDs were almost the same compared with those at the initial visit.

Abbreviations: AVG, average area; CECD, corneal endothelial cell density; CD, cell density; CT, corneal thickness; CV, coefficient of variation; HEX, hexagonal; MAX, maximum area; MIN, minimum area; NUM, number of cells. 
unclear. We previously reported a case with CECD reduction around a wasp sting wound that was present even 6 months after the incident. ${ }^{10}$ Briefly, we divided the cornea into four portions (superior, inferior, right, and left) and measured CECDs of each portion. We found that the CECDs differed across the portions (superior: 2,525 cells $/ \mathrm{mm}^{2}$, inferior: 853 cells $/ \mathrm{mm}^{2}$, right: 2,506 cells $/ \mathrm{mm}^{2}$, and left: 2,257 cells $\left./ \mathrm{mm}^{2}\right) .{ }^{10}$ In the present case, we could measure CECD in the center of the cornea only because of limitations of our measurement tools. However, even in the present case, CECDs may have differed if measured across different portions of the cornea. Amann et $\mathrm{al}^{11}$ reported that the human cornea has an increased endothelial cell density in the paracentral and peripheral regions of cornea compared with the central region. The superior peripheral region of the corneal endothelium reveals the largest increase in the endothelial cell density. ${ }^{11}$

To the best of our knowledge, there are no reports on wasp stings of the cornea when wearing eyeglasses. Our patient was stung in the cornea while playing hide-andseek in the school ground. Use of protective eyeglasses may reduce the danger of such stings. Appropriate eye protectors have been found to reduce the risk of significant eye injury at least $90 \%$ when properly fitted. ${ }^{12}$ Furthermore, the effectiveness of protective eyeglasses for dental surgeons has already been verified during daily dental works. ${ }^{13}$

Anterior chamber irrigation effectively resolved the inflammation due to the paper wasp sting of the cornea. Therefore, we propose that this method should be considered as the first choice of treatment.

\section{Informed consent}

Written informed consent was obtained from the patient's mother for publication of this case report and any accompanying images.

\section{Disclosure}

The authors report no conflicts of interest in this work.

\section{References}

1. Isawumi MA, Hassan MB. Honeybee sting of the sclera: occular features, treatment, outcome and presumed pathogenesis. Pan Afr Med J. 2014;17:30.

2. Hammel N, Bahar I. Descemet-stripping automated endothelial keratoplasty after bee sting of the cornea. J Cataract Refract Surg. 2011;37(9):1726-1728.

3. Koh N, Chiba K, Kikuchi M, Senoo T, Chigusa Y. Case report of vesicular keratitis and cataract cased by bee venom without sting. Atarashii Ganka. 2008;25(4):549-552.

4. Ono T, Iida M, Mori Y, et al. Outcomes of bee sting injury: comparison of hornet and paper wasp. Jpn J Ophthalmol. 2018;62(2):221-225.

5. Miki A, Abe T, Shiratori A, Ando N. A case of wasp sting of the cornea. Folia Ophthalmol Jpn. 1994;45:1063-1066.

6. Nakashima N, Tsukamoto H, Hirayama T. Two cases of wasp sting of the cornea resolved without paracentesis. J Hiroshima Med Assoc. 2004;57:887-889.

7. Iwami T, Nishida Y, Murata T. Two cases of wasp or bee stings on the cornea. Atarashii Ganka. 2003;20:1293-1295.

8. Habermann E. Bee and wasp venoms. Science. 1972;177(4046):314-322.

9. Raghuraman H, Chattopadhyay A. Melittin: a membrane-active peptide with diverse functions. Biosci Rep. 2007;27(4-5):189-223.

10. Mutoh T, Matsumoto Y, Chikuda M. A case of paper wasp sting of the cornea. Ganka. 2010;52:89-93.

11. Amann J, Holley GP, Lee SB, Edelhauser HF. Increased endothelial cell density in the paracentral and peripheral regions of the human cornea. Am J Ophthalmol. 2003;135(5):584-590.

12. Lorrison WI, Hersh PS, Kunzweiler T, Shingleton BJ. Sports-related ocular trauma. Ophthalmology. 1990;97(10):1265-1269.

13. Azodo CC, Ezeja EB. Ocular health practices by dental surgeons in Southern Nigeria. BMC Oral Health. 2014;14:115.
International Medical Case Reports Journal

\section{Publish your work in this journal}

The International Medical Case Reports Journal is an international, peer-reviewed open-access journal publishing original case reports from all medical specialties. Previously unpublished medical posters are also accepted relating to any area of clinical or preclinical science. Submissions should not normally exceed 2,000 words or
4 published pages including figures, diagrams and references. The manuscript management system is completely online and includes a very quick and fair peer-review system, which is all easy to use. Visit http://www.dovepress.com/testimonials.php to read real quotes from published authors. 